\title{
ESTADO Y POLÍTICA EN EL TERRITORIO NACIONAL DE MISIONES DURANTE LOS GOBIERNOS RADICALES: EL GOBERNADOR HÉCTOR BARREYRO Y LOS CONFLICTOS POLÍTICOS ENTRE AUTORIDADES (1917-1930)*
}

\author{
State and politics in the national territory of Misiones during the radical \\ administrations: governor Héctor Barreyro and political conflicts among \\ authorities (1917-1930)
}

Luz Irene Pyke**

\begin{abstract}
Resumen
El presente artículo propone indagar en las relaciones entre Estado y política en el Territorio Nacional de Misiones durante el primer ciclo de gobiernos nacionales radicales, con objetivo de observar el modo en que las formas de construcción política del radicalismo lograron encauzar conflictos entre autoridades políticas y funcionarios públicos otrora frecuentes y acrecentar la autoridad de la figura del gobernador, sin realizar modificaciones estructurales o institucionales. Entre estas formas de construcción política que se han analizado, se encuentran tanto la proliferación de comités asociados al partido radical como la emergencia de liderazgos locales, entre los que se destaca el del gobernador Héctor Barreyro. El artículo propone observar el alcance de estas formas de construcción política del radicalismo en el territorio de Misiones para acrecentar la autoridad del gobernador, a través del análisis de las características particulares de la carrera profesional y política de Barreyro, y de la forma en que se expresaron algunos conflictos políticos durante sus años en el cargo. Este análisis se ha realizado sobre fuentes de carácter oficial escritas tanto editadas como no editadas procedentes principalmente del Ministerio del Interior.
\end{abstract}

$<$ Estado $><$ conflictos políticos $><$ Territorio Nacional de Misiones $><$ radicalismo $>$

\begin{abstract}
The article inquires into the relations between the State and politics in the National Territory of Misiones during the first radical administrations. The main goal is to observe the way in which the radicalism's forms political construction managed to channel once common several conflicts between political authorities and public servants, and increase the authority of the governor, without making any structural o institutional changes. Among the forms of political construction that were analyzed, there were the proliferation of committees associated with the radical party and the emergence of local leaderships, in which governor Héctor Barreyro's political figure stands out. The article aims to observe the reach of these forms of political construction in the National Territory of Misiones to increase the authority of the governor, through the analysis of the particular features of Barreyro's professional and political career and the way in which some political conflicts emerged during his years as governor. Over official sources, both edited and unedited, from the national office of interior matters were analysed.
\end{abstract}

$<$ State $><$ political conflicts $><$ National Territory of Misiones $><$ radicalism $>$

Recibido: 30/03/2016 // Aceptado: 07/06/2016

* Una versión preliminar de este artículo fue presentada en XXXIV Encuentro de Geohistoria Regional, IIGHI-CONICET/UNNE, 2014.

** Magíster en Historia. UNMDP-CONICET. luzpyke@gmail.com 


\section{Introducción}

Las particularidades del sistema político-institucional de los Territorios Nacionales han dado lugar al desarrollo de varias investigaciones historiográficas que han buscado dar cuenta de los diversos problemas estructurales del mismo. Estos problemas tenían que ver principalmente con las relaciones entre diversas autoridades políticas y funcionarios públicos, de orden nacional o territorial, que al no encontrarse reguladas o institucionalizadas por ley, generaron frecuentes conflictos durante las primeras décadas de vida de los territorios. Los conflictos de autoridad fueron blanco de numerosas quejas principalmente por parte de los gobernadores territoriales, ya que a menudo estos conflictos tenían como objetivo principal el de horadar sus atribuciones y su lugar como máxima autoridad dentro de la estructura de gobierno de los territorios. Si bien durante la década de 1910 el gobierno nacional impulsó una reforma integral de la Ley Orgánica de Territorios Nacionales $n^{\circ} 1532 / 1884$ con el objetivo de subsanar estos problemas, ésta nunca se concretó. No obstante, al promediar el ciclo de gobiernos nacionales de signo radical a mediados de la década de 1920, los conflictos políticos más frecuentes en los territorios entre autoridades y funcionarios parecieron haberse disipado en parte.

El presente artículo propone indagar en las relaciones entre Estado y política en el Territorio Nacional de Misiones durante el primer ciclo de gobiernos nacionales radicales, con el objetivo de observar el modo en que las formas de construcción política del radicalismo lograron neutralizar estos conflictos de autoridad otrora frecuentes y acrecentar la autoridad de la figura del gobernador sin realizar modificaciones estructurales o institucionales a la Ley Orgánica de Territorios Nacionales $\mathrm{N}^{\circ}$ 1532/1884. En este sentido, el artículo se ha centrado en el análisis de la figura del gobernador del territorio de Misiones Héctor Barreyro, quien ejerció dicho cargo a lo largo de casi todo el ciclo de gobiernos radicales nacionales. Este análisis se enmarca en el actual desarrollo de la investigación para la tesis doctoral de quien escribe sobre las perspectivas y propuestas de acción de autoridades y agentes estatales del territorio de Misiones frente a movimientos políticos de características transfronterizas durante las décadas de 1920 y 1930, y buscará retomar algunas de las innovaciones teóricometodológicas de las últimas décadas en historia política.

Las fuentes analizadas fueron de carácter oficial tanto editadas como inéditas. Entre las primeras se analizaron las memorias del Ministerio del Interior editadas anualmente, que brindaron información ligada a la agenda oficial de gobierno, constituyendo además resúmenes de gestión. De carácter similar son las Memorias de Gobierno de los gobernadores del territorio de Misiones, en las que los mismos exponían los logros de su gestión y ofrecían sus propias propuestas de desarrollo. Por otra parte, de carácter inédito se han analizado los expedientes del fondo documental del Ministerio del Interior (Archivo General de la Nación, sección Archivo Intermedio) que recopilan notas, telegramas e informes en torno a determinados temas/problemas de gobierno de carácter heterogéneo provenientes de los Territorios Nacionales. El análisis de estos expedientes permitió acceder a un conjunto de documentos de circulación 
interna o no pública, producidos por diversos actores políticos en diferentes contextos y posiciones de autoridad.

El artículo se organiza en tres apartados. El primero aborda los diferentes enfoques historiográficos sobre Estado y política en los Territorios Nacionales desarrollados en las últimas décadas. El segundo apartado analiza la estructura político-administrativa de los Territorios Nacionales, particularizando sobre la evolución política del territorio de Misiones y la emergencia de conflictos políticos entre diversas autoridades durante las primeras décadas del siglo XX. Finalmente, el último apartado indaga en las formas de construcción política del radicalismo durante los años veinte y en el modo en que éstas lograron neutralizar conflictos políticos anteriormente frecuentes en el territorio de Misiones.

\section{Enfoques historiográficos sobre Estado y política en los Territorios Nacionales}

Los abordajes teórico-metodológicos sobre política y Estado en las ciencias sociales y humanísticas han atravesado una serie de transformaciones a lo largo de las últimas décadas. Durante las décadas de 1960 y 1970, la preponderancia de los enfoques socio-económicos impidieron abordar al Estado como un actor con relativa autonomía política e institucional dotado de lógicas propias de funcionamiento, para privilegiar los enfoques de carácter clasista o economicista que lo desproveían de autonomía reduciéndolo a la expresión de intereses de grupos económicos o clases sociales. No obstante, a partir de la década de 1980 emergieron un conjunto de nuevos enfoques teórico-metodológicos que han buscado colocar al Estado nuevamente en el centro de la escena para reivindicar su centralidad como un actor autónomo relevante en los procesos políticos, sociales o económicos, reconociendo sus limitaciones y sus espacios "grises", planteando además la necesidad de historizar las realidades estatales (Scokpol, Evans y Rueschemeyer, 1985; Lemperiere, 2007; Soprano y Bohoslavsky, 2010; Zimmermann y Plotkin, 2012).

En la Argentina, los aportes de la renovada historia política han hecho su propio aporte a la historización de las realidades estatales y la revalorización de lo político. Una serie de investigaciones han desafiado en la última década la imagen de un Estado nacional omnipotente, homogéneo y autocentrado. Particularmente para la etapa formativa del Estado nacional hacia fines del siglo XIX, la mirada clásica sobre la penetración de un Estado central sobre las periferias provinciales ha cedido frente a enfoques que han indagado en los procesos de negociación y conflicto entre centros y periferias, devolviendo a las provincias - o a sus elites políticas - el protagonismo en tanto formas institucionales preexistentes en la constitución del Estado nacional. En otras palabras, los nuevos enfoques han propuesto entender el Estado nacional en su etapa formativa, no como un nuevo actor emergente que se impone sobre la sociedad civil, sino como una nueva forma de organización central creada a partir de la convergencia de catorce provincias precedentes, a través de complejos procesos de adaptación, negociación o resistencia entre elites políticas locales e incluso sectores subalternos. El desplazamiento de la mirada desde el centro hacia la periferia ha 
Pyke. Estado y política en el Territorio Nacional de Misiones durante los gobiernos radicales: el gobernador Héctor...

permitido, además, indagar en los espacios o zonas "grises" de la institucionalidad del Estado, particularmente en zonas periféricas o fronterizas donde el funcionamiento institucional podía depender más de la construcción de una red de lealtades personales que de la existencia de una estructura administrativa racionalmente organizada de tipo weberiana (Míguez y Bragoni, 2010; Zimmermann y Plotkin, 2012).

Al repensar las principales hipótesis sobre la construcción y consolidación del Estado nacional a partir de una mirada más atenta a los procesos de negociaciones y conflictos entre periferia y centro, estos enfoques abren nuevos interrogantes sobre los procesos políticos de construcción estatal en espacios como los territorios nacionales. ${ }^{1} \mathrm{Sin}$ embargo, en este marco los territorios nacionales aparecen como unidades de análisis no homologables a los espacios provinciales, ya que constituían unidades administrativas creadas por el Estado nacional y no preexistentes a él, con una organización políticoinstitucional centralizada y dependiente del mismo. Sin gobiernos autónomos y con derechos políticos restringidos, en los territorios la autoridad máxima estaba representada formalmente por la figura del gobernador, quien era designado por el Poder Ejecutivo de la Nación con acuerdo del Senado, pero que debía responder en forma directa ante el Ministerio del Interior de la Nación. Subordinados a la autoridad del gobernador, se encontraban el jefe de policía, los jueces de paz, los concejos municipales y las comisiones de fomento. Los habitantes de los territorios no contaban con derecho al sufragio más que para los concejos municipales y jueces de paz de localidades con más de mil habitantes (Ruffini, 2007).

Las características del sistema político institucional de los territorios ha llamado, de este modo, la atención de los investigadores en tornos a problemas relativos a las relaciones entre los procesos de construcción estatal y lo político, en tanto ofrecen condiciones y marcos institucionales particulares dentro de los cuales se desarrollaron una multiplicidad de prácticas institucionales, políticas y eleccionarias de carácter propio. En este sentido, cuestiones relativas a los procesos de designación de gobernadores o de los procesos electorales municipales, fueron objeto de investigaciones que buscaron respuestas en torno al desarrollo de diversas prácticas políticas en estos espacios. Entre estos trabajos es posible advertir dos tendencias contrapuestas. Por un lado, se encuentran los enfoques que han enfatizado el rol centralizador del Estado nacional

\footnotetext{
Los Territorios Nacionales fueron figuras jurídico-políticas o divisiones administrativas particulares, dependientes en forma directa del gobierno nacional, con derechos políticos restringidos, y cuya organización y administración estaba dada por la Ley Orgánica de Territorios Nacionales $\mathrm{N}^{\circ} 1532$, sancionada en 1884. Como "Territorios Nacionales" se consideraron aquellos espacios que habían sido incorporados al Estado Nacional a partir de la década de 1870. En el caso del Nordeste, se trató de territorios cuyos límites se comenzaron a definir al término de la Guerra del Paraguay (1865-1870), mientras que en el Sur, se trató de territorios incorporados tras la campaña de conquista del Gral. Julio Argentino Roca en 1879, como Ministro de Guerra (Ruffini, 2007; Bandieri, 2006). En estos territorios se crearon las nueve gobernaciones de Misiones, Chaco, Formosa, La Pampa, Chubut, Neuquén, Río Negro, Santa Cruz y Tierra del Fuego, mientras que entre 1899 y 1943, también existió la de los Andes. Los Territorios Nacionales comprendían una superficie de $1.131 .923 \mathrm{~km} 2$, aproximadamente el $40 \%$ de los $2.780 .400 \mathrm{~km} 2$ de la superficie total del país, y permanecieron bajo esa condición durante cerca de setenta años, hasta que en la segunda presidencia del Gral. Juan Domingo Perón, por iniciativa del Poder Ejecutivo, fueron sancionadas las sucesivas leyes de provincialización de los territorios nacionales.
} 
respecto de los territorios nacionales, remarcado el carácter restrictivo y dependiente del sistema político-institucional de los mismos (Ruffini, 2007 y 2010). En esta tendencia a veces se ha concebido a los territorios como formas imperfectas o incompletas del sistema político-institucional nacional (Favaro, 1997). Mientras que por otra parte, se encuentran aquellos que se han centrado en las formas y prácticas políticas particulares o propias que se generaron dentro este marco, es decir, sin establecer a priori las formas o prácticas hacia las cuales era preferible, deseable o esperable su desarrollo (Arias Bucciarelli, 2012; Leoni, 2012; Gallucci, 2010; Bohoslavsky, 2010).

En este sentido, los cambios introducidos en los territorios nacionales por el proceso de ampliación democrática abierto tras la sanción de la Ley Sáenz Peña en 1912, que derivaron en el primer ciclo de gobiernos radicales, también han merecido la atención de recientes investigaciones. ${ }^{2}$ En algunos casos, los enfoques han buscado indagar en las relaciones entre organización y formas de participación política para el caso del territorio del Chaco (Leoni, 2008), mientras que en otros, se han centrado en las tensiones y conflictos políticos entre diversos actores políticos de orden nacional y territorial, en torno a problemas relativos a la designación de autoridades o los procesos eleccionarios municipales para el caso del territorio de Río Negro (Varela, 2015).

\section{Estructura político-administrativa y evolución política en el Territorio Nacional de Misiones durante las primeras décadas del siglo XX: los conflictos políticos entre autoridades y agentes estatales}

Hacia las primeras décadas del siglo XX, el Territorio Nacional de Misiones era una unidad administrativa consolidada. Los principales conflictos que se presentaron al momento de su creación en 1881 respecto de su ciudad capital, su organización políticoinstitucional y sus límites, ya habían sido superados y la agenda de gobierno para el territorio comenzaba a centrarse en otros objetivos relativos al fomento del poblamiento y la colonización, y la consolidación de la presencia del Estado en el mismo. Este proceso implicó la creación de nuevos pueblos y colonias, el desarrollo de las comunicaciones y el crecimiento del aparato estatal tanto en áreas específicas de gobierno como en áreas territoriales. Producto de ello, el territorio adquirió progresivamente una fisonomía

\footnotetext{
2 Si bien respecto del surgimiento y desarrollo del radicalismo hacia fines del siglo XIX y comienzos del XX, se han realizado aportes relevantes desde la historia política en los últimos años, el período del radicalismo en el gobierno no ha merecido suficiente atención. En este sentido, Eduardo Míguez ha señalado que si bien se dispone del trabajo clásico de David Rock (Rock, D. (1972) El Radicalismo. Buenos Aires: Amorrortu), su modelo analítico puede considerarse actualmente como "anticuado" (2012: 63). Más recientemente, las investigaciones de Virginia Persello (2007) han aportado a una mayor comprensión del radicalismo, aunque centrándose en los aspectos ligados al funcionamiento del mismo en tanto partido político desde sus orígenes hasta la actualidad. En este sentido, Persello ha indagado en la historia del partido radical a través del análisis tanto de organización como de la elaboración de una doctrina o identidad propias. La investigación de Marcela Ferrari (2008) sobre el radicalismo ha aportado por su parte, un amplio análisis prosopográfico sobre los elencos políticos durante el ciclo de gobiernos radicales de los años veinte. Sobre el impacto del proceso de ampliación democrática tras la sanción de la Ley Sáenz Peña en las provincias, se pueden destacar el aporte de Bragoni y Mellado para el caso de Mendoza (2012) y Piazzesi para el caso de Santa Fe (2009).
} 
Pyke. Estado y política en el Territorio Nacional de Misiones durante los gobiernos radicales: el gobernador Héctor...

particular, con zonas claramente diferenciadas por las características de su población, sus actividades económicas, sus medios de transporte y comunicación, y por el grado de presencia estatal en ellas. ${ }^{3}$

El primer problema que debió superar la creación del territorio de Misiones fue el de los límites con la provincia de Corrientes y el asiento de la ciudad capital; el segundo fue el de su organización político-institucional; y el tercero fue el del establecimiento de sus límites internacionales, particularmente con el Brasil. El primer problema surgió de los conflictos entre el gobierno nacional y el gobierno de Corrientes respecto de la creación del territorio de Misiones, debido a que este territorio venía siendo administrado desde el fin de la Guerra del Paraguay (1865-1870) por aquella provincia. De manera que el proyecto de federalización del territorio fue fuertemente resistido por las elites de Corrientes ya que lo consideraban parte de la provincia, donde además tenían intereses económicos relativos a la explotación de la yerba mate y la madera. La presión de estos sectores de poder provinciales determinó que la ciudad de Posadas quedara fuera del proyecto de federalización, estableciendo como capital del nuevo territorio al pueblo de Córpus, rebautizado como San Martín. No obstante, debido a la precariedad de este poblado en cuanto a infraestructura edilicia, de servicios y de transporte, el primer gobernador designado del territorio de Misiones, el coronel Rudecindo Roca (hermano del entonces Presidente de la Nación Julio. A. Roca), inició gestiones para incorporar a la ciudad de Posadas, de mayor importancia económica y social, como capital del territorio. Estas gestiones resultaron exitosas y Posadas fue cedida por Corrientes al Territorio Nacional de Misiones en agosto de 1882 (Alterach, 2001: 41).

El segundo problema relativo a la organización político-institucional del territorio fue superado en 1884 cuando se sancionó la Ley Orgánica de Territorios Nacionales $\mathrm{N}^{\circ} 1.532$ que estableció un marco regulatorio de ordenamiento administrativo y político, para las nuevas entidades jurídicas llamadas oficialmente como "Territorios Nacionales". Como se ya se ha mencionado, la organización político-institucional que la ley establecía formalmente conformaba un sistema centralizado en el gobierno nacional, desde donde se realizaban las designaciones para todos los cargos públicos, a excepción de los concejos municipales de localidades de más de mil habitantes dónde los habitantes podían elegir representantes a través del sufragio. ${ }^{4}$

Finalmente, el último problema fue el de la definición de los límites internacionales del territorio de Misiones, ya que tras la federalización quedó pendiente la resolución del límite oriental con el Brasil. Mientras que el río Paraná fue aceptado como límite con el Paraguay, y los ríos Iguazú y Uruguay como límites con el Brasil, una extensión de territorio de unos $30.200 \mathrm{~km} 2$ de superficie, hacia el este de los ríos Pepirí Guazú y San Antonio, se mantuvo indefinida ya que era disputada tanto por el gobierno

3 Sobre los procesos de poblamiento y colonización en el territorio de Misiones se pueden consultar Bartolomé (1982; 2000), Perié de Schiavoni y Souvi (1985) y Gallero (2009).

${ }^{4}$ Sobre los debates parlamentarios respecto de la Ley $N^{\circ}$ 1532/1884 se puede consultar Farías de Foulkes (1976). 
argentino como por el brasileño. Debido a esto, ambos países recurrieron al arbitraje internacional del Presidente de los Estados Unidos, Grover Cleveland. Finalmente, tras las presentaciones y argumentos de ambos países, el fallo dispuso en 1895 que los límites orientales entre Argentina y Brasil estaban demarcados por los ríos Pepirí Guazú y San Antonio, quedando el territorio disputado bajo jurisdicción brasileña, conformando actualmente la zona occidental del estado de Santa Catarina (Zouví, 2008). De este modo, al iniciarse el siglo XX, el territorio de Misiones contaba con un territorio definido, con una capital política y una organización política consolidada, al menos en términos formales.

La organización político-institucional que había sido pensada y diseñada al presentarse el proyecto de Ley Orgánica de Territorios Nacionales tuvo entre sus objetivos políticos fundamentales el de conformar una estructura política dependiente del Estado nacional, que generase gobiernos territoriales de baja autonomía, en contraste con las estructuras de los gobiernos provinciales. Por ello, todas las autoridades territoriales eran designadas por el gobierno central, y los habitantes de los territorios no contaban con derecho al sufragio, más que para los concejos municipales de localidades de más de mil habitantes (Ruffini, 2007).

No obstante, al desarrollarse el gobierno efectivo sobre los territorios, esta organización reveló un conjunto de problemas estructurales que derivaron en numerosos conflictos de autoridad. Estos conflictos se producían entre autoridades políticas y funcionarios públicos tanto nacionales como territoriales que actuaban en el territorio, por las imprecisiones de la misma Ley $\mathrm{N}^{\circ}$ 1.532/1884. Como se observa en el Tabla 1 , si bien el gobernador era la máxima autoridad del territorio, en éste convivían una serie de oficinas dependientes de los ministerios nacionales que no se encontraban sometidas a su autoridad y que actuaban con autonomía de ésta. Debido a que estas relaciones entre la gobernación y las oficinas nacionales no estaban reguladas ni estipuladas por la Ley $\mathrm{N}^{\circ} 1.532 / 1884$, las mismas transcurrían de acuerdo al criterio de los actores en el mejor de los casos, mientras que en otros, sus actividades se desarrollaban en forma paralela sin que existiera ninguna instancia centralizadora de las actividades de estas diversas oficinas (Leoni, 2012: 170-171; Ruffini, 2007: 177-179).

Si además se tiene cuenta que muchas de estas oficinas manejaban aspectos centrales de la administración territorial como las rentas o el otorgamiento de títulos de propiedad, esta organización presentaba una gobernación débil en su capacidad de gobierno y administración (Ruffini, 2007: 179). De hecho, la única institución de importancia y de amplio alcance territorial, dependiente y subordinada a la autoridad del gobernador, era la policía territorial. Entre las relaciones más conflictivas que presentaba esta estructura político-institucional se encontraban las de los gobernadores con los jueces letrados, ya que ambos reclamaban ser la figura de mayor autoridad de un territorio.Sin embargo, también se registraban conflictos entre gobernadores, jefes de policía y concejos municipales (Ruffini, 2007: 183-191; Leoni, 2012: 170-173; Moroni, 2010: 185). ${ }^{5}$

\footnotetext{
${ }_{5}$ Para un análisis pormenorizado sobre la justicia letrada en los territorios nacionales ver Moroni (2010).
} 
Pyke. Estado y política en el Territorio Nacional de Misiones durante los gobiernos radicales: el gobernador Héctor...

Tabla 1. Estructura de las autoridades, dependencias, oficinas y agencias estatales en el Territorio Nacional de Misiones (1916-1930)

\begin{tabular}{|c|c|c|c|}
\hline \multirow{16}{*}{$\begin{array}{l}\text { Poder Ejecutivo de la } \\
\text { Nación }\end{array}$} & \multirow{5}{*}{$\begin{array}{l}\text { Ministerio del } \\
\text { Interior }\end{array}$} & \multirow{3}{*}{ Gobernación } & Jefatura de Policía \\
\hline & & & $\begin{array}{l}\text { Concejos Municipales/ } \\
\text { Comisiones de Fomento }\end{array}$ \\
\hline & & & Justicia de Paz \\
\hline & & \multicolumn{2}{|c|}{ Oficina de Correos y Telégrafos } \\
\hline & & \multicolumn{2}{|c|}{ Departamento de Higiene } \\
\hline & \multirow{3}{*}{$\begin{array}{l}\text { Ministerio de } \\
\text { Hacienda }\end{array}$} & \multicolumn{2}{|c|}{ Dirección de Rentas } \\
\hline & & \multicolumn{2}{|c|}{ Dirección de Aduanas } \\
\hline & & \multicolumn{2}{|c|}{ Banco Nación } \\
\hline & Ministerio de Marina & \multicolumn{2}{|c|}{ Prefectura Naval } \\
\hline & Ministerio de Guerra & \multicolumn{2}{|c|}{ Regimientos } \\
\hline & $\begin{array}{l}\text { Ministerio de } \\
\text { Agricultura }\end{array}$ & \multicolumn{2}{|c|}{ División de Tierras y Colonias } \\
\hline & \multirow{3}{*}{$\begin{array}{l}\text { Ministerio de Justicia } \\
\text { e Instrucción Pública }\end{array}$} & \multicolumn{2}{|c|}{ Justicia Letrada } \\
\hline & & \multicolumn{2}{|c|}{ Concejo Nacional de Educación } \\
\hline & & \multicolumn{2}{|c|}{ Dirección de Cárceles } \\
\hline & \multirow{2}{*}{$\begin{array}{l}\text { Ministerio de Obras } \\
\text { Públicas }\end{array}$} & \multicolumn{2}{|c|}{ Dirección Nacional de Vialidad } \\
\hline & & \multicolumn{2}{|c|}{ Ferrocarriles Argentinos } \\
\hline
\end{tabular}

Fuente: Ley Orgánica de Territorios Nacionales $N^{\circ}$ 1532, y Leoni (2012: 171)

Estos problemas inherentes a la organización político-administrativa de los Territorios Nacionales dieron origen a conflictos y problemas de gobierno que hacia comienzos del siglo XX eran conocidos y reconocidos por las autoridades involucradas, como afirmaba la Dirección General de Territorios Nacionales en las Memorias del Ministerio del Interior en 1916:

“...es evidente que la separación actual de poderes que atribuye a cada Departamento de Estado una ingerencia (sic) directa en su administración, la multiplicidad de autoridades y complejidad de los trámites, obran en detrimento de la unidad de propósitos y rapidez de ejecución que caracterizan un buen gobierno". ${ }^{6}$

De manera que hacia comienzos del siglo XX los problemas estructurales de la organización político-institucional de los territorios no eran ignorados. El hecho de que la gobernación fuera por ley la "autoridad local superior" pero que coexistiera

${ }^{6}$ Ministerio del Interior. 1916. Memorias del Ministerio del Interior (1915-1916). Tomo II. Buenos Aires: Talleres Gráficos, pp. 13. 
con diversas oficinas nacionales que actuaban en forma autónoma a ella, constituía un sistema particular en el que mientras se buscaba una centralización en el gobierno nacional, la acción estatal y las políticas públicas territoriales se realizaban en forma descentralizada, ya que las dependencias actuaban sin relación entre sí.

Respecto de esto, algunos autores han señalado que los Territorios Nacionales constituían espacios centralizados pero no homogéneos dentro de cuya organización interna existían "cuñas" del Estado que quedaban fuera del alcance de la gobernación (Ruffini, 2007: 178); mientras que otros han caracterizado al sistema como un "régimen desconcentrado de poder" en el que se observa la delegación desde el gobierno central de funciones de escasa relevancia en contrapartida con un fuerte control centralizado de los actos ejecutados (Iribarne citado por Leoni, 2012: 170).

Esta situación motivó que durante la primera década del siglo XX se iniciara desde el gobierno nacional un proceso tendiente a reformar la Ley $\mathrm{N}^{\circ}$ 1.532/1884, que si bien no llegó a concretarse, sí permitió visibilizar algunos de los problemas fundamentales del gobierno de los Territorios Nacionales, y abrió el camino para que se generaran algunas propuestas específicas con el fin de subsanarlos (Ruffini, 2010: 5). Aunque los intentos por aumentar las facultades de los gobernadores no lograron éxito, el problema del gobierno de los Territorios Nacionales entró en agenda, sucediéndose diversas propuestas como la de crear un solo ministerio que centralizara sus asuntos. En ese marco, bajo la presidencia de Roque Saénz Peña, se creó en 1912 la Dirección General de Territorios Nacionales, a cargo del abogado Isidoro Ruiz Moreno, que tenía como objetivo centralizar la información y administración de los asuntos concernientes a éstos (Ruffini, 2010: 4). Así también, se convocó a una Conferencia de Gobernadores para 1913 que, aunque no generó reformas importantes, sí abrió una instancia de debate sobre los problemas en el gobierno de los Territorios Nacionales (Ruffini, 2010).

El territorio de Misiones no era ajeno a estos problemas comunes a otros Territorios Nacionales. Respecto de esto, puede mencionarse la respuesta del gobernador del territorio de Misiones Manuel A. Bermúdez al cuestionario enviado a los gobernadores por el ministro del Interior Montes de Oca en 1907, con el objetivo de elaborar un proyecto de reforma de la Ley $\mathrm{N}^{\circ} 1532 / 1884$, en donde aquel afirmaba:

“...el gobernador no tiene ingerencia (sic) alguna en las diversas dependencias administrativas del territorio, ni está en aptitud de conocer cómo se cumplen las leyes y disposiciones nacionales que no son de su directa incumbencia. (...) El gobernador es hoy el jefe inmediato de la gendarmería del territorio y nada más. En virtud de leyes, decretos reglamentarios y disposiciones varias, se ha ido despojando paulatinamente a los gobernadores de toda ingerencia (sic) directa en los asuntos de más vital importancia para el progreso de los territorios". ${ }^{7}$

7 Gobernación de Misiones. 1907. Informe del gobernador del territorio, Señor Manuel A. Bermúdez, contestando el cuestionario del Ministerio del Interior sobre reorganización de los territorios nacionales, Corrientes: Imprenta y Encuadernación Teodoro Heinecke, pp. 13-14. 
Pyke. Estado y política en el Territorio Nacional de Misiones durante los gobiernos radicales: el gobernador Héctor...

Posteriormente, Bermúdez pasaba a enumerar cómo los gobernadores no intervenían en "los capitales problemas de la colonización, que están hoy en manos exclusivas de la División de Tierras y Colonias del Ministerio de Agricultura", ni en "las receptorías nacionales de rentas y aduanas del territorio, porque esas oficinas dependen únicamente del ministerio de hacienda", mientras que "las sub-prefecturas y resguardos dependen en absoluto del ministerio de marina". ${ }^{8}$ Finalmente afirmaba que:
“...las oficinas técnicas de vialidad, de impuestos internos, de inmigración, los interventores de alcoholes, administradores de colonias, directores de cárceles, etc., son dependencias y empleados extraños al mecanismo gubernativo, sobre quienes no se ejerce contralor alguno, y que proceden por cuenta propia como entidades autónomas". ${ }^{9}$

Sin embargo, pese a que estos problemas estructurales eran conocidos y reconocidos por las autoridades nacionales, los intentos de reformar la Ley $\mathrm{N}^{\circ} 1532 / 1884$ fracasaron y la organización político-institucional de los Territorios Nacionales mantuvo sus rasgos fundamentales hasta los procesos de provincialización iniciados en la década de 1950. Ello no significó empero que los gobiernos nacionales no hayan prestado atención a los problemas de gobierno de los Territorios Nacionales. Lo que cambió fueron los enfoques y las prioridades en cuanto a cuáles eran las reformas que debían hacerse en ellos.

\section{El radicalismo en el territorio de Misiones: formación de comités y promoción de liderazgos locales}

Hacia la década de 1920, el radicalismo gobernante a nivel nacional se había planteado extender el ejercicio de la ciudadanía y la posibilidad de conformar gobiernos autónomos hacia los Territorios Nacionales que, según la Ley $\mathrm{N}^{\circ}$ 1532/1884, estuviesen en condiciones de hacerlo. ${ }^{10}$ En 1919, el presidente Hipólito Yrigoyen no sólo dispuso la realización de un censo de Territorios Nacionales, sino que además presentó al Congreso el primer proyecto de ley para provincializar los territorios de La Pampa y Misiones. Al anunciar el proyecto, el presidente hizo hincapié "en la responsabilidad del orden conservador en la postergación política de los territorios y el rol reparador que el radicalismo iba a emprender en los mismos". De manera que durante el gobierno

\footnotetext{
${ }_{8}^{8}$ Gobernación de Misiones. 1907. Informe del gobernador del territorio, Señor Manuel A. Bermúdez, contestando el cuestionario del Ministerio del Interior sobre reorganización de los territorios nacionales, Corrientes: Imprenta y Encuadernación Teodoro Heinecke, pp. 13-14.

9 Gobernación de Misiones. 1907. Informe del gobernador del territorio, Señor Manuel A. Bermúdez, contestando el cuestionario del Ministerio del Interior sobre reorganización de los territorios nacionales, Corrientes: Imprenta y Encuadernación Teodoro Heinecke, pp. 13-14.

${ }^{10} \mathrm{El}$ artículo $4^{\circ}$ de la Ley $\mathrm{N}^{\circ}$ 1532/1884 establecía que "cuando la población de una Gobernación alcance a sesenta mil habitantes, constatados por el censo general y los censos suplementarios sucesivos, tendrá derecho para ser declarada provincia argentina".
} 
de Yrigoyen la integración de los Territorios Nacionales al sistema político nacional se presentaba como un aspecto más de la reparación que el radicalismo proponía, subsanando la cuestión de la exclusión política (Ruffini, 2007). De hecho, entre 1916 y 1930 el bloque radical en ambas cámaras y el Poder Ejecutivo presentaron diecisiete proyectos referidos a la situación política de los Territorios Nacionales (Ruffini, 2009).

Esta intención se extendió también al gobierno de Marcelo T. de Alvear, quien en 1924 auspició un proyecto para crear legislaturas en Chaco, Misiones y La Pampa, en tanto no se resolviese la provincialización, argumentado que las mismas debían servir "para establecer el grado de capacidad cívica de los territorios, a la par de un procedimiento preparatorio para su transformación en provincias" (Favaro y Bucciarelli, 1995: 11). Es decir que la cuestión de los Territorios Nacionales formaba parte de la agenda del radicalismo desde 1919. Sin embargo, el radicalismo también estimuló formas novedosas de construcción y participación política, que introdujeron cambios en las dinámicas políticas de los territorios.

En Misiones, la década de 1920 estuvo signada, como en el resto del país, por la aparición de comités radicales cuyos miembros se disputaban -de acuerdo al sistema político de los territorios- los puestos de administración pública y los pocos electivos que existían, conformando una incipiente elite política en la ciudad capital de Posadas. Junto a este proceso también se dio la aparición de un estilo de liderazgo novedoso, representado en la figura de Héctor Barreyro, quien ejerció como gobernador durante más de diez años (Ver Tabla 2), con un breve período de ausencia, convirtiéndose en una figura de gran centralidad para la vida política de Misiones en el período.

Tabla 2. Gobernadores del Territorio Nacional de Misiones y Ministros del Interior desde 1916 hasta 1930

\begin{tabular}{|c|c|c|}
\hline Presidente & Ministro del Interior & $\begin{array}{l}\text { Gobernador del Territorio } \\
\text { Nacional de Misiones }\end{array}$ \\
\hline \multirow{3}{*}{$\begin{array}{c}\text { Hipólito Yrigoyen } \\
(12 / 10 / 1916-12 / 10 / 1922)\end{array}$} & $\begin{array}{c}\text { Ramón Gómez } \\
(12 / 19 / 1916-10 / 4 / 1922)\end{array}$ & \multirow{3}{*}{$\begin{array}{l}\text { Soriano Romero (1/12/1916- } \\
\text { 23/5/1917) } \\
\text { Héctor Barreyro } \\
(23 / 5 / 1917-27 / 4 / 1920) \\
\text { Guillermo Doll (interino) } \\
(27 / 4 / 1920-30 / 9 / 1922)\end{array}$} \\
\hline & \multirow{2}{*}{$\begin{array}{c}\text { Francisco Beiró } \\
(10 / 4 / 1922-12 / 10 / 1922)\end{array}$} & \\
\hline & & \\
\hline \multirow{3}{*}{$\begin{array}{c}\text { Marcelo T. Alvear } \\
(12 / 10 / 1922-12 / 10 / 1928)\end{array}$} & $\begin{array}{c}\text { José Nicolás Matienzo } \\
(12 / 10 / 1922-26 / 11 / 1923)\end{array}$ & \multirow{3}{*}{$\begin{array}{c}\text { Diógenes Lotero (interino) } \\
(30 / 9 / 1922-16 / 10 / 1922) \\
\text { Héctor Barreyro } \\
(16 / 10 / 1922-1 / 1 / 1930)\end{array}$} \\
\hline & $\begin{array}{c}\text { Vicente Gallo } \\
(26 / 11 / 1923-1926)\end{array}$ & \\
\hline & $\begin{array}{c}\text { José P. Tamborini } \\
(1926-12 / 10 / 1928)\end{array}$ & \\
\hline $\begin{array}{c}\text { Hipólito Yrigoyen } \\
(12 / 10 / 1928-6 / 9 / 1930)\end{array}$ & $\begin{array}{c}\text { Elpidio González } \\
(12 / 10 / 1928-6 / 9 / 1930)\end{array}$ & $\begin{array}{c}\text { José Manuel López (interino) } \\
\qquad(1 / 1 / 1930-27 / 9 / 1930)\end{array}$ \\
\hline
\end{tabular}

Fuente: Elaboración propia 
La aparición de comités radicales en la ciudad de Posadas formaba parte del modo particular de construcción política del partido radical a nivel nacional. Su organización se extendía por todo el país siguiendo el modelo de caucus (tomado del liberalismo inglés), que suponía la formación de comités electorales en los barrios de las ciudades, para desarrollar una actividad política permanente. Este sistema permitía a los intermediarios cooptar adherentes y proyectarse como dirigentes. Junto a este proceso, también se aceleró la acentuación de la autonomización de lo político al propiciar la formación de una dirigencia especializada o "clase política", conformada por políticos profesionales que vivían de y para la política, cuyas trayectorias tenían lugar dentro de los partidos políticos (Ferrari, 2008). De este modo, el radicalismo se constituyó rápidamente como una máquina política que gracias a su capacidad de expansión y movilización, logró enfrentar exitosamente los desafíos de la democracia ampliada (Ferrari, 2008; Hora, 2001; Persello, 2007).

Debido a que la Ley $\mathrm{N}^{\circ} 1532 / 1884$ establecía para los municipios de más de mil habitantes la posibilidad de conformar un concejo municipal de cinco miembros electos por sufragio, muchas figuras de la incipiente elite local desarrollaban su carrera política compitiendo para conformar el concejo municipal de Posadas. En este sentido, una de las figuras destacadas de este proceso fue Héctor Barreyro, ya que desde su labor política en los comités radicales primero y en el concejo municipal de Posadas después,logró su designación como gobernador del territorio de Misiones por parte del gobierno radical nacional en 1917.Antes de Barreyro, los gobernadores eran políticos o militares que habían hecho sus carreras políticas y profesionales en Buenos Aires, en Corrientes o en Chaco, expresando distancia respecto de la política local. La originalidad de Barreyro fue la de haber sido el primer gobernador que realizó, antes de su designación, una carrera política desde el municipio de Posadas referenciándose dentro de un partido político de orden nacional de las características del partido radical.

Barreyro nació en 1883 en Alvear, provincia de Corrientes, pero posteriormente su familia se radicó en Posadas. En Buenos Aires se recibió de médico y comenzó su vida pública en Posadas en 1907, ejerciendo como médico municipal. Su acceso a la educación superior y su ejercicio profesional de la medicina en el territorio tal vez haya constituido un atributo relevante al momento de iniciar su carrera política dentro del radicalismo. Después de la abogacía, la medicina era la segunda carrera más recurrente entre los elencos políticos del radicalismo, ya que estos profesionales eran muy valorados a comienzos del siglo XX, en tanto su capacidad de curar no sólo les confería prestigio y reconocimiento, sino que además los mantenía en contacto con todas las clases sociales, y les permitía plantear políticas que fortalecieran la salud pública (Ferrari, 2008). ${ }^{11}$

El primer cargo público de relevancia obtenido por Barreyro se dio poco después, en 1913, cuando logró la presidencia del concejo municipal de Posadas, a los 30 años de

${ }^{11}$ El análisis prosopográfico de Ferrari sobre los elencos políticos del radicalismo durante el primer ciclo de gobiernos radicales, se realizó sobre 430 personas que hicieron carrera política dentro del radicalismo en las provincias de Buenos Aires y Córdoba, ya sea como parlamentarios o como electores (Ferrari, 2008: 24). 
edad. Al año siguiente también se encontró entre las figuras destacadas que fundaron el primer comité radical en el territorio Misiones a través de un acta que establecía "formar un comité con el programa y principios sostenidos por el tradicional Partido Radical de la República". No obstante, debido al sistema político-institucional de los territorios, su actividad política y la de los demás políticos con quienes compartía estos nuevos espacios, no se enmarcaban formalmente en la estructura partidaria del radicalismo, sino en el marco de un partido local o municipal llamado "Unión Comunal" (Álvarez y Urquiza, 2010: 46).

Finalmente, en 1917 fue designado por primera vez como gobernador del Territorio Nacional de Misiones, a los 34 años de edad. Mientras los gobernadores previos no sólo eran designados por el gobierno central, sino que no tenían vínculos previos con la comunidad local, Barreyro expresaba el ascenso a la gobernación de un hombre arraigado en el territorio de Misiones, que contaba con una carrera política y profesional en Posadas, coronada por su nombramiento como gobernador, y que no adoptaba una actitud ecuánime frente a las disputas políticas del territorio como se desarrollará a continuación. Estos atributos lo colocaban lejos de una figura centrada únicamente en la administración territorial, para acercarlo a la de un líder político, similar a un caudillo.

La designación en el cargo de gobernador de un político con vínculos territoriales o "nativo" era por entonces una demanda recurrente entre diversos sectores políticos de los Territorios Nacionales. Durante las primeras décadas del siglo XX y hasta los años veinte, en los territorios se expresaba desde distintos sectores locales la demanda por gobernadores nativos. No obstante, si bien la llegada del radicalismo al gobierno nacional pareció abrir oportunidades en este sentido, la demanda no fue satisfecha en todos los casos, y cuando lo fue, no se sostuvo por períodos de tiempo muy prolongados (Leoni, 2008; Varela, 2015). En el caso del territorio de Misiones, si bien Barreyro no era misionero de nacimiento, tenía vínculos con la política local que fueron reconocidos por el radicalismo gobernante, siendo confirmado como gobernador por más de una década.

En 1919 hacia el fin de su primer período como gobernador, Barreyro publicó el memorial de su gestión bajo el título Ideas de gobierno, al contrario de sus antecesores que se conformaban con presentar "memorias" o "informes" de gestión. El texto, dirigido al ministro del Interior, decía condensar las "ideas y propósitos de gobierno" que a su entender debían "darse a la práctica a fin de encaminar el progreso del territorio", para aconsejar "soluciones que, corrigiendo deficiencias y subsanando errores, encaucen la administración pública del territorio en forma práctica y eficaz". Este informe, además de constituir una memoria de gestión, se proponía abordar los temas públicos más importantes (tierra púbica, colonización, agricultura, justicia, policía, salud, educación, etc.), repasando sus antecedentes, ofreciendo balances y proponiendo políticas específicas. La realización de esta obra nuevamente expresa, por sus características, la importancia de la educación superior como atributo del poder 
Pyke. Estado y política en el Territorio Nacional de Misiones durante los gobiernos radicales: el gobernador Héctor...

político, en tanto implicaba la capacidad para sistematizar, expresar y discutir ideas, que era muy valorada por los partidos políticos (Ferrari, 2008).

Al margen de las particularidades de los procesos políticos de cada territorio, la forma de construcción política del radicalismo nacional pareció aportar a encauzar muchos de los conflictos frecuentes en éstos, manteniendo bajo la autoridad del gobernador a muchos funcionarios y autoridades que previamente representaban amenazas para éstos. Al respecto, el informe de la Dirección General de Territorios Nacionales para las memorias del Ministerio del Interior del período 1924-1925, señalaba:

“... como expresiones demostrativas de un mejoramiento general en las condiciones de vida de los territorios puede señalarse el hecho de que no se han producido ninguno de los conflictos antes tan frecuentes, entre los gobernadores y los jueces letrados, de que han disminuido en número y en importancia las denuncias o reclamaciones por abuso de las autoridades..."12

En el territorio de Misiones, esta suerte de consenso político en los territorios tenía a Héctor Barreyro y a su forma de hacer política, como figura central. Para dar cuenta de ello, se analizarán tres hechos fundamentales que tuvieron lugar al promediar la década de 1920: los festejos por su confirmación como gobernador para un segundo mandato, las elecciones municipales de Posadas, y la creación de su propio órgano de prensa. Como se desarrollará, los tres hechos expresan el acrecentamiento de la autoridad del gobernador en detrimento de los conflictos políticos entre autoridades y funcionarios frecuentes en décadas anteriores.

Los hechos que se desencadenaron en el mes de septiembre de 1924 con motivo de la confirmación de Barreyro como gobernador por parte del Senado de la nación resultan representativos respecto del arco de apoyos políticos que éste había logrado construir en el territorio a lo largo de su carrera política, neutralizando varios de los conflictos más frecuentes de autoridad que enfrentaban los gobernadores de Territorios Nacionales. Si bien Barreyro fue designado para su segundo período como gobernador en 1922, su confirmación por parte del Senado no llegó sino hasta 1924. Cuando la noticia de ésta confirmación llegó a la ciudad de Posadas, se conformó una suerte de caravana celebratoria por el centro de la ciudad en la que manifestantes "barreyristas" marcharon "con banda de música (la policial), en automóviles o a pie”. Según denuncias posteriores presentadas ante el Ministerio del Interior, esta caravana produjo una serie de disturbios a su paso, atacando con piedras e insultos los talleres gráficos del periódico La Tarde, de filiación socialista, y a otro comité radical llamado "Marcelo T. de Alvear". Estas denuncias señalaron que entre quienes integraban la caravana se encontraban figuras locales tales como "el presidente de la municipalidad, el juez de paz titular y

\footnotetext{
${ }^{12}$ Ministerio del Interior. 1925. Memorias del Ministerio del Interior (1924-1925). Buenos Aires: Talleres
} Gráficos, pp. 150. 
varios empleados públicos", quienes buscaron en su casa al juez letrado Floricel Pérez para que ofreciera un discurso "en medio de salvadas de revólveres y gritos hostiles" hacia sectores de la oposición. ${ }^{13}$

La composición de esta caravana que contaba con la presencia del hermano del gobernador, jueces letrados y de paz, el presidente del concejo municipal y demás empleados públicos, encabezados por la banda de música de la policía, da cuenta del desarrollo de estrechas relaciones entre la burocracia estatal, la participación partidaria y el poder político. La presencia de estas figuras celebrando la designación de Barreyro, particularmente la del juez letrado, expresa además la construcción política lograda por el gobernador para mantener bajo control los conflictos que anteriormente resultaban frecuentes entre estas autoridades.

Otro de los hechos que dan cuenta de la forma en que Barreyro logró sumar voluntades entre diferentes autoridades y funcionarios para encauzar los conflictos políticos en el territorio fue la elección municipal de Posadas de $1924 .{ }^{14}$ En esta contienda electoral se enfrentaron tres fuerzas políticas, dos de las cuales decían representar en el orden local a la Unión Cívica Radical, entre las cuales se encontraba el partido municipal de Barreyro, la ex "Unión Comunal". La tercera lista la conformaba la "Unión Vecinal", antiguo partido municipal competidor de la vieja "Unión Comunal". Al momento de realizarse las elecciones, la presidencia del concejo municipal estaba en manos de Alfredo Pomar, quien era integrante la fracción radical liderada por Barreyro y buscaba la reelección en el cargo. Pese a que los gobernadores se consideraban funcionarios del Poder Ejecutivo Nacional, y que por lo tanto se esperaba cierta prescindencia o ecuanimidad política de ellos, Barreyro se involucró personalmente en las elecciones con el objetivo de favorecer a su fracción política y asegurar la relección de Pomar como presidente del concejo municipal. Habiendo iniciado su carrera política desde el municipio de Posadas, y como actual gobernador, Barreyro no sólo contaba con experiencia sino que además conocía a todos los hombres influyentes de la ciudad capital.

La abierta inclinación de Barreyro por una de las listas competidoras generó varias denuncias ante el Ministerio del Interior por parte de la fracción radical opositora a su gobierno, en las que se afirmaba que el gobernador ejercía amenazas y presiones hacia otros "caudillos radicales" para que apoyaran la lista de Pomar. Otra de las denuncias realizadas acusaba a Barreyro de haber organizado una reunión política en la casa de un concejal, donde se habría ofrecido a los electores "asado con cuero, vino y bailes". Esta versión fue contestada por el mismo concejal en cuestión quien manifestó que la reunión no había sido organizada por el gobernador sino por él mismo, en honor a éste por su reciente confirmación en el cargo. En su descargo el concejal señaló que en dicha reunión estuvieron presentes "dos jueces letrados, el jefe del distrito Militar, el

\footnotetext{
${ }^{13}$ Archivo General de la Nación, Sección Archivo Intermedio, Ministerio del Interior, Expedientes Generales, año 1924, legajo $\mathrm{N}^{\circ} 48$, expediente $\mathrm{N}^{\circ} 19745$.

${ }^{14}$ El análisis de estas elecciones municipales se realizó en base a Archivo General de la Nación, Sección Archivo Intermedio, Ministerio del Interior, Expedientes Generales, año 1924, legajo $\mathrm{N}^{\circ}$ 56, expediente $\mathrm{N}^{\circ}$ 22902; legajo $\mathrm{N}^{\circ} 62$, expediente $\mathrm{N}^{\circ} 25408$.
} 
Pyke. Estado y política en el Territorio Nacional de Misiones durante los gobiernos radicales: el gobernador Héctor...

Administrador de Rentas, [y] el Jefe de Policía" entre otros "amigos", por lo que según él nada tuvo "significado político" ya que "no se trataba de agasajar electores, sino de pasar un momento agradable en compañía del gobernador amigo". ${ }^{15}$ Estas definiciones guardan riqueza ya que dan cuenta de la importancia política de este tipo de "asados" en tanto espacios de sociabilidad política para aquellos que detentaban importantes cargos públicos en la estructura del Estado. Este hecho también expresa la amplitud de la construcción política de Barreyro al momento de sumar voluntades entre otros funcionarios que otrora podían ignorar la autoridad de los gobernadores o representar abiertas amenazas contra ésta.

Con el objetivo de ganar las elecciones municipales, Barreyro y Pomar desplegaron una serie de acciones pese a las denuncias de los sectores opositores. Entre éstas pueden señalarse el control sobre la confección de los padrones, la conformación de las mesas electorales y la entrega de certificados de identidad para electores extranjeros. ${ }^{16}$ La realización de las elecciones colocó a la lista de Pomar como triunfante, mientras que las otras dos listas declararon haberse abstenido el día de los comicios debido a las "irregularidades" que habían denunciado. De este modo Barreyro logró mantener al municipio de Posadas bajo el gobierno de su fracción radical.

En el desarrollo de estas elecciones municipales se replicaban situaciones que tenían lugar en otros escenarios del país, provinciales y territoriales. Como ha señalado Persello, el radicalismo en tanto partido predominante, si bien ocupaba en muchos casos los lugares de gobierno y de oposición (radicales coyunturalmente no oficialistas), también se disputaba los espacios representativos en una arena electoral competitiva que no podía calificarse como fraudulenta. Sin embargo, era frecuente que aquellos sectores coyunturalmente opositores recurrieran a la abstención y a las denuncias sobre "presiones oficiales" para explicar sus fracasos electorales. Estas presiones, se encontraban institucionalizadas en una suerte de máquina formada por funcionarios y empleados públicos que trabajaban en favor de un determinado candidato (Persello, 2007).

Tanto en el caso de las denuncias presentadas ante el Ministerio del Interior por disturbios durante la caravana "barreyrista" como por las irregularidades en los comicios de Posadas, se hicieron presentes las voces de otros actores políticos que

\footnotetext{
${ }^{15}$ Archivo General de la Nación, Sección Archivo Intermedio, Ministerio del Interior, Expedientes Generales, año 1924, legajo $\mathrm{N}^{\circ} 56$, expediente $\mathrm{N}^{\circ} 22902$; legajo $\mathrm{N}^{\circ} 62$, expediente $\mathrm{N}^{\circ} 25408$.

16 En el plano de las picardías electorales, utilizaron la cartelería para desautorizar a sus detractores. A través de la confección de un afiche acusaron al representante de la otra facción radical, León Naboulet, como un "ácrata" que usurpaba el nombre del Partido Radical, agregando además una fotografía de éste. En contraposición, la propaganda de su lista contaba con una fotografía de Héctor Barreyro junto a una de Leandro N. Alem, con una leyenda que lo señalaba como el "organizador del radicalismo en Misiones", seguida de los nombres de sus candidatos municipales, que se presentaban como los "genuinos representantes de la Unión Cívica Radical". Entre los valores y objetivos que decía representar, colocaban al "progreso edilicio", la "honradez" en el manejo de "los intereses públicos" y "la dignidad, la moralidad y la democracia". Archivo General de la Nación, Sección Archivo Intermedio, Ministerio del Interior, Expedientes Generales, año 1924, legajo $\mathrm{N}^{\circ}$ 56, expediente $\mathrm{N}^{\circ} 22902$; legajo $\mathrm{N}^{\circ}$ 62, expediente $\mathrm{N}^{\circ} 25408$.
} 
buscaban referenciarse desde el territorio en el radicalismo nacional. Estos sectores buscaban a través de sus denuncias influir de alguna manera en el concepto que los ministros nacionales pudieran tener sobre el gobernador, ya que una de las formas de disputar dicho cargo era a través de la política nacional, debido a las características del sistema político-institucional de los Territorios Nacionales. Sin embargo, en ambos casos el entonces ministro del Interior, Vicente Gallo (1923-1926), se pronunció en favor del gobernador, desestimando las denuncias de sus detractores.

Hacia mediados de 1925, Héctor Barreyro logró concretar otro proyecto tendiente a acrecentar su poder político: la fundación de un periódico propio. Hasta ese entonces, el espectro de periódicos más importantes en Posadas estaba conformado por el diario $L a$ Tarde, que se decía independiente pero que en verdad respondía al socialismo, el diario La Reacción, que era un órgano de prensa de la fracción radical contraria a Barreyro, y el boletín La Nueva Época, afín al gobierno del territorio. Todos estos periódicos se enmarcaban en lo que se puede definir como "diarios políticos", ya que se encontraban ligados estrechamente al sistema político (por sus finanzas, su personal y posibilidad de supervivencia) y conformaban una suerte de "opinión pública" local (Duncan, 2007). La Reacción por caso, se definía lisa y llanamente como un órgano sostenedor de "los principios de la Unión Cívica Radical”, rendidores "de culto a Alem”, y seguidores de Yrigoyen como "único Jefe”. La Tarde por su parte se definía como un "diario independiente, noticioso, comercial, científico, literario y de intereses generales", lo que lo hacía más atractivo y menos faccioso. Finalmente La Nueva Época, órgano con el que contó Barreyro durante sus primeros años de gobierno territorial, era un boletín de una sola cara impresa que no ofrecía mayores atractivos. Los periódicos constituían entonces un ámbito público de discusión de ideas y propuestas políticas, aunque muchas veces se pasara en sus páginas a los ataques personales de todo tipo (Zimmermann, 1998). Estos elementos eran los que permitían afirmar a Ramón Cárcano en 1883, que "un diario para un hombre público es como un cuchillo para el gaucho pendenciero: debe tenerse siempre a mano" (Duncan, 2007: 66).

En este contexto, el periódico El Territorio salió por primera vez el 2 de Junio de 1925, bajo la dirección del dirigente radical Sesostris Olmedo, con un perfil fuertemente alineado al gobernador. Además de contar con mayor cantidad de páginas que los demás periódicos, a los clásicos editoriales políticos y cables nacionales e internacionales se agregaban una sección de noticias provenientes de diferentes pueblos del interior del territorio gracias a una red de corresponsales, y una sección de "sociales". Finalmente, en lugar de definirse políticamente en tapa como lo hacían los demás periódicos, El Territorio simplemente se jactaba de ser "el diario de mayor circulación de Misiones". Este periódico presentaba así un formato más moderno y atractivo que sus competidores, lo que pudo haber contribuido a su permanencia en el tiempo como uno de los periódicos más influyentes de Misiones hasta el presente. ${ }^{17} \mathrm{El}$ impulso a la creación de un nuevo órgano de prensa por parte de Barreyro, podría enmarcarse entonces dentro

\footnotetext{
${ }^{17}$ Actualmente el diario El Territorio continúa publicándose diariamente desde la ciudad de Posadas,
} constituyendo el órgano de prensa más antiguo de la provincia de Misiones. 
Pyke. Estado y política en el Territorio Nacional de Misiones durante los gobiernos radicales: el gobernador Héctor...

de una estrategia mayor tendiente a acrecentar su poder político en tanto gobernador del territorio, sin necesidad de echar mano a ningún tipo de reforma de carácter institucional.

Barreyro finalizó su último mandato como gobernador en enero de 1930, meses antes del golpe de Estado del 6 de septiembre de 1930, encabezado por el General José Félix Uriburu. No obstante el ex gobernador continuó desarrollando actividades políticas relevantes en el territorio de Misiones durante los años treinta. En las elecciones municipales del 6 de noviembre de 1932 se postuló como concejal del municipio de Posadas obteniendo el triunfo y resultando electo como presidente del flamante concejo municipal. ${ }^{18}$ Sin embargo, debido a la abierta oposición que Barreyro le ofrecía al entonces gobernador Carlos Acuña (1930-1935), fue encarcelado y despojado de su cargo, bajo la excusa de haber estado involucrado en las conspiraciones radicales de Atilio Cattáneo. Posteriormente, también tuvo una activa y destacada participación en las campañas provincialistas del territorio. ${ }^{19}$

\section{Conclusiones}

El análisis que se ha propuesto ha permitido abordar algunas de las formas en que la construcción política del radicalismo logró, en el territorio de Misiones, acrecentar la autoridad de la figura del gobernador, neutralizando o encauzando conflictos antiguamente frecuentes, sin realizar modificaciones estructurales o institucionales a la Ley $\mathrm{N}^{\circ} 1532 / 1884$. Como se ha señalado, la proliferación de comités radicales en el país permitió la proyección de liderazgos políticos de orden local. Este proceso en Misiones se expresó a través del liderazgo de Héctor Barreyro quien no sólo constituía un cuadro político del radicalismo con pertenencia territorial, sino que también contaba con una carrera profesional y política en la ciudad capital del territorio, desde la cual había demostrado su capacidad para competir electoralmente en forma exitosa. Si bien esta capacidad de liderazgo de Barreyro pudo deberse en parte a sus atributos personales, las formas de construcción política del radicalismo pudieron haber contribuido al desarrollo de las relaciones entre la burocracia estatal, la participación partidaria y el poder político que se ha observado en el proceso analizado. Los apoyos que Barreyro logró consolidar hacia su liderazgo entre otras autoridades políticas y funcionarios en el territorio pudieron ser además una de la claves para comprender el apoyo que éste recibió por parte del gobierno nacional durante más de una década.

\footnotetext{
${ }^{18}$ Estas elecciones habían sido convocadas por el gobierno de Agustín Pedro Justo con el objetivo de normalizar la situación de los municipios electivos de los territorios que habían sido intervenidos durante el gobierno de Uriburu (Arias Bucciarelli, 2012).

${ }^{19}$ Olmedo S. y Herrera M. 1935. Misiones bajo el terror. Posadas.
} 


\section{Referencias bibliográficas}

Fuentes editadas

Barreyro, H. 1919. Ideas de gobierno. Buenos Aires: Talleres Gráficos.

Gobernación de Misiones. 1907. Informe del gobernador del territorio, Señor Manuel A. Bermúdez, contestando el cuestionario del Ministerio del Interior sobre reorganización de los territorios nacionales. Corrientes: Imprenta y Encuadernación Teodoro Heinecke.

Ley Orgánica de Territorios Nacionales № 1532/1884.

Ministerio del Interior. 1916. Memorias del Ministerio del Interior (1915-1916). Tomo II. Buenos Aires: Talleres Gráficos.

Ministerio del Interior. 1925. Memorias del Ministerio del Interior (1924-1925). Buenos Aires: Talleres Gráficos.

Olmedo S. y Herrera M. 1935. Misiones bajo el terror. Posadas.

\section{Fuentes inéditas}

Archivo General de la Nación, Sección Archivo Intermedio, Ministerio del Interior, Expedientes Generales, año 1924, legajo $\mathrm{N}^{\circ} 48$, expediente $\mathrm{N}^{\circ} 19745$; legajo $\mathrm{N}^{\circ}$ 56 , expediente $\mathrm{N}^{\circ} 22902$; legajo $\mathrm{N}^{\circ} 62$, expediente $\mathrm{N}^{\circ} 25408$.

\section{Bibliografía}

Alterach, M. Á. 2001. Rudecindo, el otro descubiertero. Buenos Aires: Dunken.

Álvarez, N. 1994. Las voces del radicalismo: las posibilidades de las fuentes orales en la construcción de la historia de Misiones. Posadas: Inédito.

Álvarez, N. 2008. En defensa de la democracia: la contrarrevolución en Misiones (1930-1933). En XXVIII Encuentro de Geohistoria Regional, UNNE-IIGHI, Resistencia.

Álvarez, N., y Urquiza, Y. 2010. Misiones entre la provincialización y la dictadura (1953-1976). Posadas: Editorial Universitaria.

Arias Bucciarelli, M. 2012. "La municipalización de lo político. Constroversias y debates en el Primer Congreso de territorios acionales." En M. Arias Bucciarelli (Ed.), Diez territorios nacionales y catorce provincias. Argentina, 1860-1950. Buenos Aires: Prometeo.

Bandieri, S. 2006. Historia de la Patagonia. Buenos Aires: Prometeo.

Bartolomé, L. 1982. “Colonias y colonizadores en Misiones.” Instituto de Investigación, Facultad de Humanidades Y Ciencias Sociales, Universidad Nacional de Misiones, Posadas.

Bartolomé, L. 2000. Los colonos de Apóstoles. Estrategias adaptativas y etnicidad en una colonia eslava en Misiones. Posadas: Editorial Universitaria de Misiones.

Bohoslavsky, E. 2010. “Clase y ciudadanía en los conflictos sociales y políticos en el extremo sur de Argentina y Chile a principios del siglo XX." In E. Bohoslavsky y M. Godoy Orellana (Eds.), Construcción estatal, orden oligárquico y respuestas sociales. Argentina y Chile, 1840-1930. (pp. 265-290). Buenos Aires: Prometeo. 
Pyke. Estado y política en el Territorio Nacional de Misiones durante los gobiernos radicales: el gobernador Héctor...

Bragoni, B., \& Mellado, V. 2012. Civitistas, populares, radicales y lencinistas: partidos y competencia electoral en Mendoza (1912-1918). Estudios Sociales, 205-234.

Bragoni, B., \&Míguez, E. 2010. Un nuevo orden político. Provincias y Estado Nacional, 1852-1880. Buenos Aires: Editorial Biblos.

Duncan, T. 2007. "La prensa política: Sud-América, 1884-1892”. Revista de Instituciones, Ideas y Mercados, $\mathrm{n}^{\circ}$ 46, pp. 65-92.

Farías de Foulkes, A. R. 1976. "El debate parlamentario sobre la Ley 1532 de Territorios Nacionales." Folia Histórica Del Nordeste, (2), IIGHI, UNNE, pp. 72-99.

Favaro, O. 1997. "Realidades contrapuestas a los estados provinciales: los territorios nacionales, 1884-1955." Realidad Económica, (144), 79-96.

Ferrari, M. 2008. Los políticos en la república radical. Buenos Aires: Siglo XXI.

Gallero, M. C. 2009. Con la patria a cuestas. La inmigración alemana-brasileña en la Colonia Puerto Rico, Misiones. Buenos Aires: Araucaria Editora, IIGHI.

Gallucci, L. 2010. "Ciudadanía y orden institucional en la Patagonia Norte. Notables y subalternos en Neuquén durante las primeras décadas del siglo XX." En E. Bohoslavsky y M. Godoy Orellana(Eds.), Construcción estatal, orden oligárquico y respuestas sociales. Argentina y Chile, 1840-1930.. Buenos Aires: Prometeo, pp. 291-319.

Hora, R. 2001. Autonomistas, radicales y mitristas: el orden oligárquico en la provincia de Buenos Aires (1880-1912). Boletín Del Instituo de Historia Argentina $Y$ Americana “Dr. Emilio Ravignani,"3(23), 39-77.

Lemperiere, A. 2007. "La historiografía del Estado en Hispanoamérica.” En G. Palacios (Ed.), Ensayos sobre la historia política de América Latina, siglo XIX. México: El Colegio de México.

Leoni, M. S. 2008. La política en el Chaco en la primera mitad del siglo XX. Estructuras de participación, actores y prácticas. In G. Iuorno\& E. Crespo (Eds.), Nuevos Espacios. Nuevos Problemas. Los territorios nacionales. Neuquén: Educo.

Leoni, M. S. 2012. "Vínculos entre la política nacional, regional y local. La designación de gobernadores en los Territorios Nacionales." En M. S. Leoni y M. del M. Solís Carnicer (Eds.), La politica en los espacios subnacionales. Provincias $y$ Territorios en el nordeste argentino (1880-1955) (pp. 167-183). Rosario: Prohistoria.

Leoni, M. S., y Solís Carnicer, M. del M. 2012. La política en los espacios subnacionales. Provincias y Territorios en el nordeste argentino (1880-1955). Rosario: Prohistoria.

Míguez, E. 2012. Gestación, auge y crisis del orden político oligárquico en la Argentina. Balance de la historiografía reciente. PolHis, V(9), 38-68.

Moroni, M. 2010. "Diseño para el ensayo y el error. La Justicia letrada y los jueces en el Territorio Nacional de La Pampa (1884-1934).” En A. Luch y M. Moroni (Eds.), Tierra adentro... Instituciones económicas y sociales en los Territorios Nacionales (1884-1951). (pp. 183-201). Rosario: Prohistoria.

Perié de Schiavoni, Á., y Zouví, S. 1985. "La colonización en Misiones : 1a. parte (Contexto internacional, nacional y sus antecedentes).” Instituto de Investigación, 
Facultad de Humanidades Y Ciencias Sociales, Universidad Nacional de Misiones.

Persello, A. V. 2007. Historia del radicalismo. Buenos Aires: Edhasa.

Piazzesi, S. 2009. La trastienda de un estreno. Las elecciones presidenciales de 1916 en Santa Fe. Estudios Sociales Contemporáneos, (3), 103-122.

Ruffini, M. 2007. Le pervivencia de la República posible en los territorios nacionales. Poder y ciudadanía en Río Negro. Buenos Aires: UNQui.

Ruffini, M. 2010. "Ecos del Centenario. La apertura de un espacio de deliberación para los Territorios Nacionales: la Primera Conferencia de Gobernadores (1913)." RevistaPilquen, XII(12), 1-12.

Skocpol, T., Evans, P., y Rueschemeyer, D. (Eds.). 1985. Bringing the State back in. Cambridge UniversityPress.

Soprano, G., y Bohoslavsky, E. 2010. Un Estado con rostro humano. Buenos Aires: Prometeo.

Varela, M. T. (2015). Estado y Territorios Nacionales .Relaciones, tensiones y conflictos en la sociedad y la politica rionegrina (1916-1943). Universidad Nacional de La Plata.

Zimmermann, E. 1998. "La prensa y la oposición política en la Argentina de comienzos de siglo: el caso de 'La Nación' y el Partido Republicano". Estudios Sociales, $\mathrm{n}^{\circ}$ 15.

Zimmermann, E., y Plotkin, M. 2012. Los saberes del Estado. Buenos Aires: Edhasa.

Zouvi, S. 2008. "La Federalización de Misiones." En G. Iuorno y E. Crespo (Eds.), Nuevos Espacios. Nuevos problemas. Los territorios nacionales. Neuquén: Educo-Universidad Nacional del Comahue-Universidad Nacional de la Patagonia San Juan Bosco-Cehepyc. 